\begin{abstract}
Today's workplace is becoming more multinational and culturally diverse than ever, both in terms of U.S. organizational employment and the greater global economy. While interest in cross-cultural training has grown as a result, however, there remains a dearth of scientific theory and empirical investigation supporting it. More specifically, there is scant information on key competencies that are needed for employees to perform global work effectively. This work addresses this gap in knowledge by briefly reviewing the history and current state of cultural competency across disciplines. A systematic and qualitative literature review of 39 studies, each involving empirically-tested cross-cultural interventions, was conducted. We review empirical and field-based research to distill and define cultural competencies that are key for modern organizations, proposing a novel framework that also incorporates corresponding interventional methods. Nine key competencies are identified and categorized into a novel theoretical framework of three domains. We conclude by making practical, scientifically-backed recommendations for scientists and practitioners alike.
\end{abstract}




\section{Clarifying competencies: A qualitative synthesis of cross-cultural training objectives}

In today's climate, organizations must respond to an increasingly diverse workforce and global economy. In the U.S., the proportion of people of color in the workplace is projected to increase greatly, such that there will be no racial or ethnic majority in the country by 2050 (Cardenas, Ajinkya, \& Gibbs Leger, 2011). Further, in that time, immigrants and their families will grow to account for $83 \%$ of the working-age population (Burns, Barton, \& Kerby, 2012). Such multiculturalism is especially relevant to multinational organizations - beyond influencing the internal compositional diversity of employees, these issues significantly impact the ways in which global work is performed. Thanks to major advances in technology and transportation, multinational organizations collaborate across geographic distances and perform work embedded in varying national cultures and contexts (Hinds, Liu, \& Lyon, 2011). Indeed, the number of expatriates, or employees deployed overseas, is estimated to be close to one million worldwide and likely to continue to grow (Mercer, 2009). These trends point towards the critical importance of creating culturally aware and sensitive organizations, particularly through cross-cultural training.

Cross-cultural training (CCT), broadly, refers to formal efforts to prepare people for more effective interpersonal relations and job success upon interacting with culturally diverse others (Brislin \& Yoshida, 1993). While these cultural faultlines have typically been conceptualized in terms of nationality or ethnicity, we herein take a broader definition of culture, used by Cross and colleagues (1989) and echoed by other culture researchers (e.g., Triandis \& Suh, 2002): an "integrated pattern of human behavior that includes thoughts, communications, actions, customs, beliefs, values and institutions of a racial, ethnic, religious or social group" (p. 28). Culture is 
pervasive in its influence, framing societal, organizational and individual experiences, in the workplace and beyond. As such, it has become critical to modern organizations - from private businesses to governmental agencies - to understand the roles in which it drives our intra- and intergroup interactions, personally and professionally.

Traditionally, CCT has focused on issues of expatriation and repatriation (that is, preparing people to live and work abroad and assisting them in their return to their home country following completion of the assignment; (Littrell, Salas, Hess, Paley, \& Riedel, 2006; R. Michael Paige, 1986). In the same way that culture can be explored within a group, however, CCT also can be implemented domestically (e.g., preparing people within one's own country to better deal with those who are from other groups, such as religious or ethnic minorities; Bhawuk \& Brislin, 2000). Indeed, as cultures blend and blur over time, it becomes increasingly important to see $\mathrm{CCT}$ as a bridge both between and within groups.

The literature has supported the effectiveness of CCTs. Meta-analytic reviews have found that CCTs results in positive outcomes across several dimensions: self-efficacy, including self-confidence and well-being; skill development, both interpersonally and cognitively; and expatriate performance and adjustment, measured through early return rates and supervisor ratings (Black \& Mendenhall, 1990; Morris \& Robie, 2001). These findings are borne out across industries. For example, within multinational corporations, CCTs have been found to facilitate expatriate effectiveness (Littrell \& Salas, 2005), by increasing expatriate adjustability, which in turn positively influences performance (Caligiuri, Phillips, Lazarova, Tarique, \& Burgi, 2001; Deshpande \& Viswesvaran, 1992). These effects are seen within multicultural populations, as well. Within healthcare, meta-analyses have found that training physicians in cultural 
competencies can improve critical service-oriented knowledge, skills, and attitudes, ultimately resulting in higher patient satisfaction (Beach et al., 2005; Smedley, Stith, \& Nelson, 2003). Overall, the empirical evidence point towards the value of CCTs.

Despite this body of research, however, major theoretical issues continue to plague the understanding and adoption of CCT strategies. Its study across different and non-overlapping fields inherently has resulted in fragmented and incomplete conceptualizations. More specifically, there is scant information on key competencies that are needed for employees to perform cross-cultural work effectively. Herein, competencies refer to identifiable sets of behaviors, which are attributable to individuals and instrumental in the delivery of desired results or outcomes (Bartram, 2005; Tett, Guterman, Bleier, \& Murphy, 2000). The aforementioned definition by Cross and colleagues (1989) places emphasis on organizations, given that their conceptualization targets larger healthcare systems. The U.S. Army Research Institute, on the other hand, focuses more on individual knowledge, skills, and affective states that enable one to adapt effectively in cross-cultural environments (Abbe, Gulick, \& Herman, 2007a). Across corporate research, conceptualizations of cultural competency vary widely, often focusing on item-specific goals (e.g., as awareness of global economies, broad multicultural knowledge, and interpersonal openness) rather than singular definitions (Adler \& Bartholomew, 1992). In short, cultural competencies mean different things, and serve different purposes, depending on who's being asked. For organizations to perform cross-cultural work maximally and effectively, it is necessary to identify clearly and develop the essential cultural competencies.

This has unfortunate repercussions, given that researchers are unable to translate their advances into practice without keener understanding of cultural influences (Littrell \& Salas, 
2005). In practice, organizations have not yet adopted many proposed global work strategies due to controversies surrounding goals, content, effectiveness, implementation, and processes of cross-cultural trainings (Baumgarten, 1995; Brewster, 1995; Selmer, 2001; Selmer, Torbiorn, \& de Leon, 1998; Tung, 1982). Leadership remains skeptical of CCTs Baumgarten, 1995; Bhagat \& Prien, 1996; Black \& Mendenhall, 1990; Brewster, 1995; Deshpande \& Viswesvaran, 1992), resulting in only an estimated third of organizations offer their employees cross-cultural trainings, (Bhagat \& Prien, 1996; Black, 1988; Deshpande \& Viswesvaran, 1992)As a result, many expatriate managers are unsuccessful in foreign organizations, failing to meet performance objectives and, in many cases, returning early from assignments (Baumgarten, 1995; R. Bennett, Aston, \& Colquhoun, 2000; Bhagat \& Prien, 1996; Littrell et al., 2006; Rahim, 1983). In the words of Littrell and colleagues, organizations "are not listening" or implementing cross-cultural initiatives, (2006, p. 358), defying claims that such training is necessary for increased effectiveness (Black \& Mendenhall, 1990; Tung, 1982). Despite growing awareness of multicultural matters, the field has faced many issues in fully understanding and maximizing its research and practice.

This research aims to address a specific gap in the CCT literature by clarifying the competencies. Given these concerns, we hereby present an integrative, qualitative review of the cultural competency literature. First, we systematically search and review empirical research to extract specific competencies. Second, we synthesize these attributes into a standardized framework, drawing from theoretical work. Finally, we identify implications, for both practitioners and academics alike, which will maximize CCT effectiveness and research.

\section{Methods}


This qualitative review of CCT competencies began with a systematic literature search. In order to tap into the most current, relevant findings in a quickly-growing research area, we limited our investigation to articles published in 1997 and after. We used Business Source Complete, MasterFile Premier, and PsycINFO, to locate relevant peer-reviewed journal articles, searching within abstracts for the terms cultural, cross-cultural, multicultural, multi-cultural, intercultural, and culture. These were each crossed with words indicative of training: training, intervention, education, management, program, workshop, initiative, course, teaching, and instruction. When possible, these terms were entered as wildcard operators in order to include all possible lexical derivatives. This returned an initial pool of 2,260 peer-reviewed articles. Supplementary searches, using the aforementioned parameters, were conducted using Google Scholar in an effort to identify any additional articles.

In order to determine eligibility, we reviewed peer-reviewed articles that described and evaluated a CCT. This criterion ensured that our findings were relevant from both an academic and practitioner standpoint: extrapolated from empirical research and connected to practices in the field. Specifically, the articles had to evaluate a training using a method of comparison - either repeated measures or independent groups study designs. Given that we were examining competencies, studies were eliminated if they did not clearly identify the cultural competencies being trained. This included studies that listed criteria that were too broad (for example, general domains, such as "knowledge" and "skills") or too narrow (e.g., specific items of a questionnaire) as dimensions of assessment. Based on these parameters, 39 articles were included in the analyses.

\section{Analyses}


Braun and Clarke (2006)'s guidelines for thematic analysis were used to guide the qualitative coding process. After reviewing each article, we identified and coded the competencies of the training program(s), as specified in the descriptions of the curriculum (e.g., learning objectives or content). Once we generated a comprehensive list of codes, these were examined for redundancy. Multiple codes were collapsed into one overarching label if they measured the same underlying construct (e.g., flexibility and openness were subsumed under the greater competency of adaptability). These competencies were then sorted into a standard framework.

In general, competencies needed for effective job performance have been sorted into the standard domains of knowledge, skills, and abilities (and, in many cases, a fourth category of other abilities; Campion et al., 2011). Recent research has suggested, however, that the domain of "attitudes" may appropriately supplant "abilities" and "other abilities," particularly when psychosocial constructs such as culture are being investigated (Abbe et al., 2007a; Byram \& Nichols, 2001; Epstein \& Hundert, 2002; McLagan, 1997). This modification also allows interdisciplinary alignment with Bloom (1964)'s seminal taxonomy of learning objectives: cognitive (knowledge), psychomotor (skills), and affective (attitude) outcomes. These categorizations of competency modeling and learning provide a practical, theoretically-sound template upon which to sort the identified competencies: knowledge, skills, and attitudes.

Once we synthesized and organized these competencies, we augmented findings with insight from the CCT literature. Specifically, we connected each of these domains and categories with types of training programs. Following population of the framework, we examined the articles for common themes and supplemented implications with those from the literature. These are presented below. 


\section{Results}

\section{Competency Framework}

Based on our findings, we identified several major competencies that we believe to be important for effective cross-cultural work, shown in Table 2. Each competency was identified in at least one empirical study as a desired outcome of a culturally-focused intervention. The resultant list, while not meant to be exhaustive, is a representative span of competencies targeted in today's global workplace.

\section{Knowledge}

The knowledge domain encapsulates all information specific to a cultural assignment. That is, it typically involves declarative, or factual, knowledge of the cultural environment. As such, the major competency comprising this domain is straightforward: knowledge of other cultures. This construct comprises a wealth of information that is often crucial for effective global work. As such, a great number of training methods have emerged in order to best facilitate the transmission of knowledge of other cultures, including cognitive-behavior modification, didactic, and interaction trainings. Each of these methods serves to better orient employees, and in particular expatriates and geographically mobile individuals, to new and foreign cultures.

Cultural knowledge. This competency, most broadly, refers to the factual knowledge related to other cultures. The scope of such content can range from more general areas (e.g., politics, economics, religion and history) to more specific characteristics (such as food, gender relationships, and culturally appropriate gestures; Kealey \& Protheroe, 1996; Morris \& Robie, 2001; Wexley \& Latham, 2002). This is particularly important for employees involved with particular cultures, such as expatriates in foreign countries and public servants in community 
settings, who must interact with diverse clientele (Lasch, Wilkes, Lee, \& Blanchard, 2000;

Littrell et al., 2006). In the case of the former, employees of multinational organizations must be aware of social norms that may guide business interactions and transactional outcomes; in the case of the latter, for example, health providers should understand cultural beliefs that may impact a family and patient's medical decision-making. In such circumstances, it is critical for employees to demonstrate a comprehensive cultural understanding of a host nation or target demographic.

Interventions. The most appropriate training methods for contextual competencies focus on the transfer of assignment-specific knowledge. Didactic training, which is fact-oriented, is the most common and straightforward interventional method for knowledge-based competencies. It involves the distribution of written materials that compare countries in terms of working conditions, living conditions, and cultural differences (J. M. Bennett, 1986), and can also include more diverse topics, such as travel arrangements, job characteristics, shopping, and appropriate dress characteristics for work (Littrell \& Salas, 2005). Through the provision of such information, didactic training aims to enhance trainees' cognitive skills that enable them to understand and develop a framework through which they may evaluate the host culture and its resultant new situations (Littrell \& Salas, 2005). Delivery methods may encompass a wide variety of activities, such as informal briefings, traditional formal educational activities, and culture assimilators (Brewster, 1995).

While didactic training can be appropriate across a broad number of situations, two knowledge-oriented interventional methods are available specifically to expatriates. Cognitive-behavior modification training, proposed by Black and Mendenhall (1990), is modeled 
after clinical models of cognitive-behavioral therapy and aims to develop habitual behaviors desired in the host culture (Bhawuk, 2001; Brislin \& Bhawuk, 1999). The training focuses on helping the expatriate go beyond identifying and avoiding behaviors that would be inappropriate by also teaching behaviors that would be typically rewarded in the host culture (Befus, 1988). While cognitive-behavior modification training requires discrete, interventional time, interaction training is built on learning on the job. The incoming expatriate learns directly from the incumbent whom he or she is replacing (Befus, 1988). Incoming expatriates are sent to the foreign country prior to the departure of the incumbent for a period of "overlap" (Littrell \& Salas, 2005). While both employees are in the host country, the experienced expatriate may facilitate hands-on business training, introductions to key persons, and adjustment to the host culture (Littrell \& Salas, 2005). Each of these methods targets building individual knowledge and cognitive abilities in specific cultural contexts.

\section{Skills}

In contrast to knowledge, these behaviorally-based competencies are more generalizable across situations. However, while they are useful to individuals in isolation, skills are more effective when adapted to a cultural assignment. In context, they can be developed and sharpened over time, with a spectrum of mastery or maturity. While skills often refer to more technical strategies, in the CCT context, these often refer to more amorphous social and personal constructs. Perhaps unsurprisingly, during literature search and review, many articles identified skill-based competencies as an objective, but did not specify the exact strategy (e.g., “interpersonal skills"). Regardless, our qualitative analyses revealed that major skills were highlighted by a number of CCTs, including communication, cultural self-efficacy, and 
perceptual acuity, which can be targeted through (roughly respectively) language, experiential, and attributional interventions.

Communication. Communication is an inherent, critical part of effective work, be it local, global or virtual. Therefore, it was no surprise that over one third of the articles explicitly named communication as a targeted training competency. However, in diverse settings, it takes on special import as cultural differences can increase the opportunity for misunderstanding. Effective communication can involve several aspects, depending on the needs of the particular cultural assignment. In the case of those serving diverse populations, it involves recognizing barriers and challenges to effective communication and using appropriate modes in response (Assemi, Cullander, \& Hudmon, 2004). In practice, this may mean selecting clear wording, listening to the client or customer, and ensuring understanding through closed-loop communication. Of note, however, is the fact that communication need not be limited to spoken language; it refers to both appropriate verbal and nonverbal responses (Dogra, Reitmanova, \& Carter-Pokras, 2010).

Expatriation may require additional communicative competency; that is, employees must possess or develop functional fluency in the host nation's language in order to effectively conduct work transactions. It is important to note, however, that while ideal, it is not always critical for one to become experts in a given language. The attempt to speak another language may be a small gesture, but it is often greatly appreciated due to its demonstration of interest in the culture (Gudykunst, Guzley, \& Hammer, 1996). One word of caution, however, is that there are some high-stakes environments in which subpar use of language could be detrimental. For example, in healthcare, it is critical to have expertise in translation when conveying medical 
information. In such situations, there are still specific skills (such as interaction with interpreters) that can increase communicative efficacy across language barriers. Given its importance in both internal and external affairs, communication should be a key skill emphasized in any organization's cross-cultural program.

Perceptual acuity. Culture colors the lens through which people perceive the world, including the ways in which they interpret the actions of others. Individuals often encounter difficulties when understanding the meaning and causes of behavior in those from unfamiliar cultures. For example, employees can default to attributional techniques from their native county when assigning meaning to the behavior of foreign others (Befus, 1988). This often results in misinterpretation of action and miscommunication. In order to prevent these errors, which may negatively influence organizational decision-making, employees should develop perceptual acuity when interacting with representatives from other cultures. Employees of multinational and culturally diverse organizations should be able to place others' behaviors into culturally appropriate contexts, thereby more accurately interpreting intentions; such insight will then allow them to make more comprehensive and informed business decisions.

Cultural self-efficacy. Bandura defined self-efficacy as individual beliefs and expectations concerning personal mastery (1977) - that is, self-confidence in one's own ability to deal with stressors (Schwarzer, Bäßler, Kwiatek, Schröder, \& Zhang, 1997). While self-efficacy has been investigated as a generalized belief system, it has more often been conceptualized as a domain-specific characteristic, sensitive to different domains or particular situations of functioning (Schwarzer, Bäßler, Kwiatek, Schröder, \& Zhang, 1997. In particular, cultural self-efficacy has been operationalized as personal perceptions of communication skills, cultural 
assessment skills, and cultural knowledge in interacting with diverse populations (Bernal \& Froman, 1993; St Clair \& McKenry, 1999). It is critical that employees feel capable in culturally diverse settings, given that self-efficacy influences the initiation and persistence of behavior (Bandura, 1977). When employees feel confident in their environs (e.g., through extensive preparation and training), their performance and satisfaction increases (Becker, Huselid, Pickus, \& Spratt, 1997; Hutchings, Zhu, Cooper, Zhang, \& Shao, 2009).

Interventions. Given the inherent emphasis on skill-building in this domain, it follows that many of the corresponding interventional methods draw largely on hands-on techniques. Arguably the most active form of CCT can be found in intercultural experiential training, in which individuals are encouraged to "learn by doing." The programs center upon role-playing and experiential exercises designed to increase awareness of other cultures and openness to unfamiliar modes of behavior and value systems (Wexley \& Latham, 2002), and can include activities such as look-see visits, role-playing, intercultural workshops, and simulations (Grove \& Torbiorn, 1993; Kealey \& Protheroe, 1996; Morris \& Robie, 2001). Experiential training intends to build the skills necessary for: performing work functions effectively; interacting positively and communicating effectively with others; and acquiring the skills needed to make correct attributions and respond in culturally appropriate manners (Kealey \& Protheroe, 1996; Morris \& Robie, 2001). Furthermore, following these interventions, expatriates should be able to take on the host national's perspective and respond to situations as though they were a member of said culture (Morris \& Robie, 2001). Organizations can further target perceptual acuity through specialized interventions. 
Attribution training addresses errors by focusing on the development of attitude and skills necessary for adoption of the host culture's attributional practices (Befus, 1988). Brislin and Bhawuk advocated that all CCTs should endeavor to teach participants how to make appropriate isomorphic attributions (that is, judgments regarding the causes of behavior) and handle disconfirmed expectations (Brislin \& Bhawuk, 1999). That is, not only should participants learn to attribute behavior in a manner similar to host nationals, but they should also feel comfortable when observing behavior that does not align with their expectations. Together, these two abilities support an open mindset, which can lead to more adaptable, flexible schema and greater cultural understanding, increasing the likelihood of successful expatriate adjustment.

Finally, one specialized area of interest in cross-cultural training involves the transmitter of culture itself - language. Today, U.S. employees must develop basic language skills to be able to communicate with colleagues and customers from foreign countries. While it is not relevant in all cases, language training can be crucial to certain assignments, such as when expatriates relocate to areas with different official languages or when public servants must serve diverse communities. In many businesses, language training focuses on providing individuals with the ability to exchange common courtesies in the host language. In addition to helping trainees convey sincerity, language training can also improve on-the-job performance. Having functional command of a non-native language can increase the speed with which individuals process data, thereby ensuring that the employee avoids missing crucial pieces of information (Ashamalla \& Crocitto, 1997). Individuals who have at least a rudimentary grasp of the language will, therefore, be more effective in new, foreign-speaking work environments.

\section{Attitudes}


The final domain focuses on competencies that revolve around individual differences. These are attitudinal and affective competencies, centered on cultivating psychosocial characteristics that give way to cross-cultural effectiveness: adaptability, awareness, motivation, open-mindedness, and resilience. Due to their internal focus, these competencies are also typically "portable," in that they train broadly useful competencies that are generalizable across assignments. Cultural awareness trainings can create environments of introspection, supportive of the development of these trait-like competencies. Furthermore, organizations can focus these individual skills on specific levels of relationships -- for example, intraorganizational relations between diverse employees or externally with client-facing representatives.

Adaptability. Adaptability refers to an individual's flexibility and openness in approaching novel situations. It can be conceptualized as "behavioral code-shifting," in which individuals can authentically and appropriately react to aspects of other cultures (J. M. Bennett, 1986). Adaptability also involves the extent to which a person can receive, evaluate and act on relevant, external information, without hindering influence by internal bias, personal expectations, or other confounding environmental data (Kelley \& Myers, 1993; Majumdar, Keystone, \& Cuttress, 1999). In a recent review on cross-cultural training, Littrell and Salas cite that adaptability is a burgeoning area of research (2005) -- that is, researchers are focusing on how to best cultivate adaptability in individuals and under what conditions. This construct also taps into resilience, which has been advanced as a critical part of cross-cultural adjustment (Abbe, Gulick, \& Herman, 2007b; Befus, 1988; Pan, Wong, Chan, \& Joubert, 2008). Adaptability will surely emerge as a critical competency in a fast-paced, modernizing economy, inherently influencing the ability of employees to acquire and refine other knowledge and skills. 
Awareness. Over half of the reviewed studies targeted the development of awareness, or the understanding of one's own culture and professional background. While it certainly involves sensitivity to others' belief systems, it is predicated on the the self-awareness of the assumptions that drives one as an individual. Indeed, the development of awareness entails the acknowledgement of the prejudices, biases, stereotypes, and beliefs that one holds regarding others who are different from them (e.g., Campinha-Bacote, 2002; Leininger \& McFarland, 2002). In the context of cross-cultural work, awareness is valuable and necessary because individuals risk of imposing their own beliefs, morals, and norms otherwise. This potentially unwelcome projection of one's own culture on another could potentially lead to conflict, whether subtle or overt, among cross-cultural team members, demanding mental energy that would otherwise be spent on productive work activities. It follows that an employee's lack of cultural awareness could thus negatively impact on an organization's bottom line. For this reason, cultural awareness should be one of the primary competencies developed in employees who will engage in cross-cultural work assignments.

Motivation. This construct has been conceptualized in a number of ways, including “cultural desire" (Berlin, Nilsson, \& Törnkvist, 2010; Campinha-Bacote, 2002) and "intent to change behavior" (Bhawuk, 1998). Overall, however, this competency describes an employee's motivation to engage in the processes of becoming aware, knowledgeable, skillful, and familiar with cultural encounters (Campinha-Bacote, 2002). On a more philosophical level, it can describe a genuine aspiration to be open and flexible, to accept differences and build on similarities, and to be willing to learn from others as cultural informants (Campinha-Bacote, 2002; Tervalon \& Murray-García, 1998). It is critical that employees possess authentic desires to 
engage with and learn from culturally different others, as it will naturally influence interpersonal interactions and consequent organizational transactions (such as negotiations).

Open-mindedness. Open-mindedness encompasses a combination of both respect for cultural differences and cultural empathy, or the ability to symbolically position oneself in another culture. It involves two components: mutual respect, or the holding of other cultures on equal footing as one's own; and perspective-taking, the ability to empathize with the "other," or member of the out-group. Altogether, these dynamics create more compassionate and sensitive attitudes. Dogra conceptualized this competency as the attitude "that cultures can come together in a positive way" (2010, p. 238), which is thus inherently and significantly related to positive attitudes toward diverse others (Bonaparte, 1979). This objectivity is, unsurprisingly, imperative for effective and collaborative work in a cross-cultural context. That is, employees who work alongside colleagues, customers, and/or supervisors from other cultures, whether as part of an assignment abroad as an expatriate or locally in a group comprised of individuals from other backgrounds, must exhibit appreciation for the diversity that characterizes their team. Of note, open-mindedness is distinctly different from awareness through the orientation of two competencies; awareness is internally-focused (on one's own culture), while open-mindedness is externally-focused (on cultures other than one's own).

Resilience. Resilience, as a cultural competency, broadly refers to the characteristic or practice of recovering from, overcoming, or successfully adjusting to adverse circumstances or life stresses (e.g., (Grotberg, 2003; Masten, Best, \& Garmezy, 1990; Pan et al., 2008). In their studies of cross-cultural competencies specifically, Lievens, Harris, Van Keer, and Bisqueret (2003) define resilience as the ability to keep difficulties in perspective and to remain positive 
despite disappointment and obstacles, while Majumdar, Keystone, and Cuttress (1999)

conceptualize resilience as the ability to cope with stressful situations and to interact with others in a new or unfamiliar setting, asserting that individuals with this competency would seek out new experiences while simultaneously learning from their mistakes. With the increasingly global nature of workplaces today, the likelihood of employees encountering difficulties during the transition process is high, making resilience critical to successful expatriation and global work. Resilience is also critical to the internally-facing performance of employees. For example, public servants who deal with diverse populations (e.g., law enforcement officers serving low-income areas) must be able to manage culturally challenging interactions in order to perform and carry out their duties effectively. Having this elastic mindset can serve a broad swath of industries, from private corporations to government agencies.

Interventions. Given that individual competencies are largely attitudinally-focused, the most effective type of training focuses on encouraging individuals to introspect. $\underline{\text { Cultural }}$ awareness training, also known as sensitivity training, focuses on educating individuals about their own culture, such that they will better appreciate differences between their native and other cultures (Befus, 1988). The content may focus on providing trainees the opportunity to explore their own interpersonal styles, basic values, and attributions, especially as colored by their own cultures. This type of training may be implemented among expatriates (pre-departure or during the assignment) or as a general organizational intervention, given its broad goals. While the previous knowledge- and skill-based interventions aim to impart technical knowledge and skills, sensitivity training attempts to calibrate a trainee's attitudes and affect surrounding cultural bases 
of behavior. This holistic sense of awareness can then improve trainee sensitivity to the self and the environment (Wexley \& Latham, 2002).

\section{Discussion}

Throughout this paper, we've implemented a systematic, qualitative literature review and proposed a framework to identify core cultural competencies and corresponding organizational interventions. However, it should be noted that these individual competencies do not exist in a vacuum. They interact with, and influence, one another significantly and dynamically. For example, resilience (an attitudinal competency) can guide the ways in which employees communicate (a skill-based competency). Black and Gregerson observed that successful expatriates possessed a sense of tenacity when learning the language of their host country, unafraid of making and learning from their errors (1999). Adaptability is yet another example of a competency which can influence and encapsulate a host of characteristics, including emotional resilience and perceptual acuity (Kelley \& Myers, 1993). Isolating these competencies is useful in that organizations can better identify areas of need and target their interventions; however, it is key to understand that these are living constructs that naturally and holistically contribute to greater cross-cultural effectiveness.

\section{Recommendations}

Clearly identify target cultural competencies. This classification can help organizations ensure that the needs of trainees are being met by elucidating the entire spectrum of relevant cross-cultural competencies. This framework and its sample competencies are proposed as a launching point for application in the workplace; it is not meant to be an exhaustive list of knowledge, skills, and attitudes. However, it does provide a reference point for 
common, empirically-tested competencies upon which organizations can draw. It is important to note that these should be used in combination with other general training principles. For example, programs should take care to accurately assess the needs of their organizations and address them through intervention design. To this end, Littrell and Salas (2005) argue that organizations must use a skill-based approach by first conducting a cognitive task analysis (CTA). CTAs help identify the competencies required for successful performance during overseas deployment, which can then be used to tailor cross-cultural training learning objectives.

Understanding the needs of the CCT can assist researchers and practitioners in clearly identifying the cultural competencies being targeted. An impressive number of studies often did not explicitly list their targeted competencies or comparable outcomes, and were eliminated from review as a result. Further, cultural competencies were identified inconsistently within the methodology - e.g., in the description of the program content (as a course objective) or in the means of assessment (in the description of an evaluative instrument). Ideally, cultural competencies should be outlined clearly in both: stated and incorporated in the curricular goals and explicitly, empirically assessed post-intervention. Currently, there is a lack of consistency and transparency in cross-cultural interventions regarding the way it is communicated and measured. This, in turn, contributes to the issue of ambiguity plaguing the field in practice.

Empirically assess target cultural competencies. One critical finding in this study was that few studies evaluated their training outcomes in a clear, comprehensive, and functional manner. We eliminated 96 studies from review, given that they did not assess training outcomes through meaningful quantitative comparison. This trend is also distinguishable outside of the peer-reviewed literature. For example, Azad and colleagues (2002) found in a review of 16 
Canadian medical schools' curriculum, only half integrated cultural sensitivity into their curriculum; of these, only one formally evaluated it as a course objective. Again, here, general training practices should apply; evaluation is critical to ensuring the effectiveness and viability of a program. As in any other type of training, the goals must be made obvious and quantifiable. It is critical to identify these cultural competencies as it underscores why these interventions are valid and contribute to organizations.

\section{Practitioners}

\section{Understand when to target knowledge, skill, or attitude-based cultural}

competencies. While this framework was developed through an investigation of existing cross-cultural trainings, its applications can be much broader. The tripartite taxonomy can help organizations strategize how and at what stage they target these competencies. Knowledge competencies are the most practical dimension for training, as they typically involve declarative facts related to specific assignments or circumstances. Indeed, many researchers argue that tailoring the trainings to individual expatriate experiences is superior (Bhawuk, 2001; Brislin \& Bhawuk, 1999). Conversely, skills and attitudinal competencies can be emphasized by organizations at the selection or training stages. In an investigation linking selection and training of cross-cultural competencies, Lievens, Harris, Van Keer, and Bisqueret (2003) found that individual-level variables measured at the selection stage (e.g., Openness) predicted future performance in cross-cultural training programs. Given this translational finding, organizations can strategize which cross-cultural competencies to emphasize during various processes in human resources management. 


\section{Develop more effective cross-cultural trainings through based on the specificity of}

competencies. In a more training-specific context, the proposed framework can help HR professionals design and target their intervention - from more general, individual emphasis to specific, contextual foci. For example, an organization with diverse employees may choose to focus on individual, attitudinal competencies, since these portable behaviors will transfer across environments. However, if a company has already determined specific assignments for overseas deployment of employees, it may choose to augment such training with more specific, knowledge-based information, such that expatriates will be prepared to enter a new culture with more ease. Indeed, researchers have developed scales that bisect cultural knowledge, skills, and attitudes based on generality or specificity (Bernal \& Froman, 1993; St Clair \& McKenry, 1999), underscoring the importance of this manner of distinction. In line with this, the proposed framework makes clear which domains of competencies are germane with an organization and its needs.

\section{Researchers}

Study cross-cultural issues as a unique, singular subfield. As aforementioned, one of the major problems plaguing cross-cultural competency is its theoretical ambiguity. In organizations, cross-cultural themes are often dismissed or folded into larger overarching issues of diversity (e.g., in order to cut costs or consolidate training time). Indeed, in a recent meta-analysis, Kalinoski et al. (2013) merged review of diversity trainings and cross-cultural interventions, contending that, despite having different samples with disparate motivations, the content and purpose of both interventions were similar enough to warrant combination. While cross-cultural issues can be incorporated appropriately into diversity trainings (e.g., for 
meta-analytic purposes), circumstances often also may call for attention and action beyond diversity-related initiatives. Our framework makes clear that cross-cultural components are singularly important and can contribute uniquely to organizations. That is, cross-cultural curricula can include knowledge-based modules, which are not inherently required in diversity trainings (e.g., cultural sensitivity). As Bhawuk and Brislin (2000) noted, cross-cultural serves multiple purposes - it does not only prepare people to live abroad, but also introduces culturally appropriate behaviors to organizations as well. Cross-cultural research serves a broad number of meaningful purposes, and therefore deserves special attention as a unique contribution to organizations.

\section{Future directions}

This is an initial step in developing a framework for a nascent literature. Despite the recency of this body of work, we reviewed the literature with the intention of building off a solid empirical foundation, hence the criterion of examining only studies based on comprehensively evaluated programs. As a result, there was a small number of articles eligible for review. As more research is conducted in other domains, so too can we expect findings from diverse realms to inform our understanding of cross-cultural competencies. As more attention is paid to the issue of cross-cultural work, we hope to see studies that empirically develop and evaluate cross-cultural trainings.

Furthermore, while this work very intentionally focused on empirically-based interventions, there were theoretical and qualitative pieces with findings that deserve future investigation. For example, Caligiuri and Di Santo (2001) conducted focus groups with global leaders, generating eight developmental goals of global competence. Other studies may have also 
generated competencies that may not have been captured in our framework due to lack of empirical testing. Future research can empirically examine these theoretically promising principles and lend it the backing of science.

\section{Conclusion}

Given the increasingly global economy, interest in cross-cultural issues is growing rapidly. Indeed, academics and practitioners from various fields and industries have proposed models, made observations, and tested interventions focusing on culturally collaborative work. However, as a whole, the research has been dispersed and piecemeal, examined from differing lenses with various emphases and methodology and resulting in divergent recommendations. There is scant research that identifies the common cultural thread running through studies and unites them into a cohesive and accessible framework. This qualitative synthesis attempts to make sense of a fragmented literature, connecting theory with empirical findings, offering best practices in research and industry, and setting the stage for further, much-needed research in the area of cultural competency. 


\section{Tables}

Table 1

Articles included in qualitative review

\begin{tabular}{|c|c|c|c|}
\hline Author (Year) & $\begin{array}{c}\text { Sample population } \\
\text { type }\end{array}$ & Design & KSAO \\
\hline Assemi et al., 2004 & Pharmacy students & Repeated measures & $\begin{array}{l}\text { Knowledge, } \\
\text { skills }\end{array}$ \\
\hline $\begin{array}{l}\text { Baker \& Delpechitre, } \\
2016\end{array}$ & Sales students & Repeated measures & $\begin{array}{l}\text { Knowledge, } \\
\text { skills, attitudes }\end{array}$ \\
\hline Bhawuk, 1998 & $\begin{array}{l}\text { Undergraduate } \\
\text { exchange students }\end{array}$ & Repeated measures & $\begin{array}{l}\text { Knowledge, } \\
\text { skills, attitudes }\end{array}$ \\
\hline Brown, 2004 & $\begin{array}{l}\text { Undergraduate } \\
\text { students }\end{array}$ & Repeated measures & $\begin{array}{l}\text { Knowledge, } \\
\text { skills, attitudes }\end{array}$ \\
\hline $\begin{array}{l}\text { Bücker \& Korzilius, } \\
2015\end{array}$ & Management students & $\begin{array}{l}\text { Independent groups, } \\
\text { repeated measures }\end{array}$ & $\begin{array}{l}\text { Knowledge, } \\
\text { skills, attitudes }\end{array}$ \\
\hline $\begin{array}{l}\text { Cahoon, Surface, } \\
\text { Towler, \& Dierdorff, } \\
2011\end{array}$ & Military professionals & Repeated measures & $\begin{array}{l}\text { Knowledge, } \\
\text { skills }\end{array}$ \\
\hline Chapman \& Hall, 2016 & Middle school teachers & Repeated measures & $\begin{array}{l}\text { Knowledge, } \\
\text { attitudes }\end{array}$ \\
\hline Chappell, 2014 & $\begin{array}{l}\text { Undergraduate } \\
\text { students }\end{array}$ & $\begin{array}{l}\text { Independent groups, } \\
\text { repeated measures }\end{array}$ & $\begin{array}{l}\text { Knowledge, } \\
\text { attitudes }\end{array}$ \\
\hline $\begin{array}{l}\text { Crandall, George, } \\
\text { Marion, \& Davis, } 2003\end{array}$ & Physicians & Repeated measures & $\begin{array}{l}\text { Knowledge, } \\
\text { skills }\end{array}$ \\
\hline $\begin{array}{l}\text { Delphin-Rittmon et al., } \\
2016\end{array}$ & $\begin{array}{l}\text { Community mental } \\
\text { health service } \\
\text { providers }\end{array}$ & Repeated measures & $\begin{array}{l}\text { Knowledge, } \\
\text { skills, attitudes }\end{array}$ \\
\hline
\end{tabular}




\begin{tabular}{|c|c|c|c|}
\hline Eisenberg et al., 2013 & $\begin{array}{l}\text { Undergraduate } \\
\text { students; management } \\
\text { students }\end{array}$ & $\begin{array}{l}\text { Repeated measures; } \\
\text { independent groups, } \\
\text { repeated measures }\end{array}$ & Skills \\
\hline Fan \& Lai, 2014 & Graduate students & $\begin{array}{l}\text { Independent groups, } \\
\text { repeated measures }\end{array}$ & Skills, attitudes \\
\hline $\begin{array}{l}\text { Farnill, Todisco, } \\
\text { Hayes, \& Bartlett, } 1997\end{array}$ & Physicians & Repeated measures & Skills, attitudes \\
\hline Flavin, 1997 & Nurses & Repeated measures & $\begin{array}{l}\text { Knowledge, } \\
\text { attitudes }\end{array}$ \\
\hline Gannon \& Poon, 1997 & MBA students & Repeated measures & $\begin{array}{l}\text { Knowledge, } \\
\text { attitudes }\end{array}$ \\
\hline Griswold et al., 2006 & Medical students & Repeated measures & Skills, attitudes \\
\hline $\begin{array}{l}\text { Hardacker, Rubinstein, } \\
\text { Hotton, \& Houlberg, } \\
2014\end{array}$ & Health professionals & Repeated measures & Knowledge \\
\hline $\begin{array}{l}\text { Harris, McQuery, } \\
\text { Raab, \& Elmore, } 2008\end{array}$ & Medical residents & Repeated measures & $\begin{array}{l}\text { Knowledge, } \\
\text { skills, attitudes }\end{array}$ \\
\hline Hayes et al., 2004 & $\begin{array}{l}\text { Mental health } \\
\text { counselors }\end{array}$ & $\begin{array}{l}\text { Independent groups, } \\
\text { repeated measures }\end{array}$ & $\begin{array}{l}\text { Knowledge, } \\
\text { attitudes }\end{array}$ \\
\hline $\begin{array}{l}\text { Ho, Yao, Lee, Beach, } \\
\& \text { Green, } 2008\end{array}$ & Medical students & Repeated measures & $\begin{array}{l}\text { Knowledge, } \\
\text { skills, attitudes }\end{array}$ \\
\hline $\begin{array}{l}\text { Ho, Yao, Lee, Hwang, } \\
\& \text { Beach, } 2010\end{array}$ & Medical students & $\begin{array}{l}\text { Independent groups, } \\
\text { repeated measures }\end{array}$ & $\begin{array}{l}\text { Knowledge, } \\
\text { skills, attitudes }\end{array}$ \\
\hline $\begin{array}{l}\text { Lawrence, Zuckerman, } \\
\text { Smith, \& Liu, } 2012\end{array}$ & Social workers & Repeated measures & $\begin{array}{l}\text { Knowledge, } \\
\text { attitudes }\end{array}$ \\
\hline $\begin{array}{l}\text { Leyva, Breshears, \& } \\
\text { Ringstad, } 2014\end{array}$ & Mental health workers & Repeated measures & $\begin{array}{l}\text { Knowledge, } \\
\text { skills, attitudes }\end{array}$ \\
\hline
\end{tabular}




\begin{tabular}{|c|c|c|c|}
\hline $\begin{array}{l}\text { Lokkesmoe, Kuchinke, } \\
\text { \& Ardichvili, } 2016\end{array}$ & $\begin{array}{l}\text { Undergraduate } \\
\text { students }\end{array}$ & Repeated measures & $\begin{array}{l}\text { Knowledge, } \\
\text { skills }\end{array}$ \\
\hline Majumdar et al., 1999 & Medical residents & $\begin{array}{l}\text { Independent groups, } \\
\text { repeated measures }\end{array}$ & $\begin{array}{l}\text { Knowledge, } \\
\text { skills, attitudes }\end{array}$ \\
\hline Neville et al., 1996 & Graduate students & Repeated measures & $\begin{array}{l}\text { Knowledge, } \\
\text { attitudes }\end{array}$ \\
\hline Numata, 2013 & $\begin{array}{l}\text { Undergraduate } \\
\text { students }\end{array}$ & Repeated measures & Skills \\
\hline $\begin{array}{l}\text { Parker, Moore, \& } \\
\text { Neimeyer, } 1998\end{array}$ & Graduate students & $\begin{array}{l}\text { Independent groups, } \\
\text { repeated measures }\end{array}$ & $\begin{array}{l}\text { Knowledge, } \\
\text { skills, attitudes }\end{array}$ \\
\hline Pedersen, 2010 & $\begin{array}{l}\text { Undergraduate } \\
\text { students }\end{array}$ & $\begin{array}{l}\text { Independent groups, } \\
\text { repeated measures }\end{array}$ & Attitudes \\
\hline Probst, 2003 & $\begin{array}{l}\text { Undergraduate } \\
\text { students }\end{array}$ & $\begin{array}{l}\text { Independent groups, } \\
\text { repeated measures }\end{array}$ & $\begin{array}{l}\text { Knowledge, } \\
\text { skills, attitudes }\end{array}$ \\
\hline $\begin{array}{l}\text { Ramsey \& Lorenz, } \\
2016\end{array}$ & Management students & $\begin{array}{l}\text { Independent groups, } \\
\text { repeated measures }\end{array}$ & Knowledge \\
\hline $\begin{array}{l}\text { Rehg, Gundlach, \& } \\
\text { Grigorian, } 2012\end{array}$ & $\begin{array}{l}\text { Military professionals } \\
\text { and government } \\
\text { civilians }\end{array}$ & Repeated measures & Knowledge \\
\hline $\begin{array}{l}\text { Robinson \& Bradley, } \\
1997\end{array}$ & $\begin{array}{l}\text { Undergraduate } \\
\text { students }\end{array}$ & $\begin{array}{l}\text { Independent groups, } \\
\text { repeated measures }\end{array}$ & $\begin{array}{l}\text { Knowledge, } \\
\text { attitudes }\end{array}$ \\
\hline Sizoo \& Serrie, 2004 & $\begin{array}{l}\text { Undergraduate } \\
\text { students }\end{array}$ & $\begin{array}{l}\text { Independent groups, } \\
\text { repeated measures }\end{array}$ & Skills, attitudes \\
\hline Spears, 2004 & & & Attitudes \\
\hline $\begin{array}{l}\text { Tarique \& Caligiuri, } \\
2009\end{array}$ & Graduate students & $\begin{array}{l}\text { Independent groups, } \\
\text { repeated measures }\end{array}$ & \\
\hline
\end{tabular}




\begin{tabular}{|l|l|l|l|}
\hline $\begin{array}{l}\text { Thom, Tirado, Woon, } \\
\text { \& McBride, 2006 }\end{array}$ & Physicians & $\begin{array}{l}\text { Independent groups, } \\
\text { repeated measures }\end{array}$ & $\begin{array}{l}\text { Knowledge, } \\
\text { skills }\end{array}$ \\
\hline $\begin{array}{l}\text { Trent, Pernell, Mungai, } \\
\text { \& Chimedza, 1998 }\end{array}$ & Teachers & $\begin{array}{l}\text { Independent groups, } \\
\text { repeated measures }\end{array}$ & $\begin{array}{l}\text { Knowledge, } \\
\text { skills, attitudes }\end{array}$ \\
\hline Williams, 2006 & Social workers & $\begin{array}{l}\text { Independent groups, } \\
\text { repeated measures }\end{array}$ & $\begin{array}{l}\text { Knowledge, } \\
\text { skills }\end{array}$ \\
\hline
\end{tabular}


Table 2

A proposed framework of cultural competencies

\begin{tabular}{|l|l|l|l|}
\hline \multicolumn{1}{|c|}{ Domain } & \multicolumn{1}{|c|}{$\begin{array}{c}\text { Learning } \\
\text { objective }\end{array}$} & Sample competencies & \multicolumn{1}{c|}{ Training methods } \\
\hline Knowledge & Cognitive & Cultural knowledge & $\begin{array}{l}\text { Cognitive-behavior } \\
\text { modification } \\
\text { Didactic } \\
\text { Interaction }\end{array}$ \\
\hline Skills & Behavioral & $\begin{array}{l}\text { Communication } \\
\text { Perceptual acuity } \\
\text { Cultural self-efficacy }\end{array}$ & $\begin{array}{l}\text { Attribution } \\
\text { Experiential } \\
\text { Language }\end{array}$ \\
\hline Attitudes & Affective & $\begin{array}{l}\text { Adaptability } \\
\text { Awareness } \\
\text { Motivation } \\
\text { Open-mindedness } \\
\text { Resilience }\end{array}$ & Cultural awareness \\
\hline
\end{tabular}

